\title{
Reduction of peripheral blood lymphocytes in patients receiving gold therapy for rheumatoid arthritis
}

\author{
JOHN G HANLY, AND BARRY BRESNIHAN \\ From the Department of Rheumatology, St Vincent's Hospital Dublin 4
}

SUMmaRY Peripheral blood lymphocytes were monitored prospectively in 10 patients with rheumatoid arthritis (RA) receiving up to $1 \mathrm{~g}$ of sodium aurothiomalate. There was a significant fall in the absolute lymphocyte count from a mean \pm SEM of $1956 \pm 190 / \mathrm{mm}^{3}\left(1 \cdot 956 \pm 0 \cdot 19 \times 10^{9} / 1\right)$ to $1232 \pm 210 / \mathrm{mm}^{3}\left(1 \cdot 232 \pm 0 \cdot 21 \times 10^{9} / \mathrm{l}\right)(\mathrm{p}<0 \cdot 01)$. The number of circulating lymphocytes fell in all patients by an amount which ranged between $108 / \mathrm{mm}^{3}\left(0 \cdot 108 \times 10^{9} / \mathrm{l}\right)$ and $1394 / \mathrm{mm}^{3}$ $\left(1.394 \times 10^{9} / 1\right)$, with a mean fall of $727 / \mathrm{mm}^{3}\left(0 \cdot 727 \times 10^{9} / 1\right)$. No significant change was noted in the total white cell count or total polymorphonuclear cell count over the same period. In contrast there was no change in the total lymphocyte count in an age and sex matched group of RA patients treated with penicillamine. This previously unreported observation may give new insight into the mechanism of action of gold salts in RA.

Lymphocytes are thought to play an important part in the pathogenesis of rheumatoid arthritis (RA), being present in large numbers in rheumatoid synovial membrane and synovial fluid. In clinical studies of RA lymphocyte depletion by thoracic duct drainage $^{1}$ or lymphapheresis ${ }^{2}$ was associated with clinical improvement, while reinfusion of lymphocytes caused a transient exacerbation. ${ }^{1}$ Gold salts are known to alter functionally peripheral blood (PB) lymphocytes ${ }^{34}$ and to modify disease activity. ${ }^{6}$ However, despite many previous clinical and laboratory studies of gold therapy there is no reference to changes in lymphocyte numbers. While evaluating patients receiving sodium aurothiomalate we noted a persistent fall in PB lymphocytes. This paper reports changes in PB lymphocyte numbers in patients beginning gold therapy.

\section{Patients and methods}

Ten patients with definite or classical RA, ${ }^{7}$ attending the rheumatology outpatient department at St Vincent's Hospital, were studied. There were eight females and two males, with a mean age of 54 years and a mean disease duration of 4.6 years. Nine patients were seropositive by RA latex fixation.

Accepted for publication 2 October 1984.

Correspondence to Dr B Bresnihan.
Joint erosions on plain $x$-rays of hands and feet were present in eight patients. All were taking various non-steroidal anti-inflammatory drugs, but none had previously been treated with remittive antirheumatic agents.

Patients were assessed before and, when possible, after receiving 250,500 , and $1000 \mathrm{mg}$ of sodium aurothiomalate, which was given in weekly increments of $50 \mathrm{mg}$ by intramuscular injection. During treatment every effort was made to maintain the patients' analgesic and anti-inflammatory medications at a constant level. Shortly after beginning sodium aurothiomalate three patients received a short course of oral prednisolone, which was tapered as rapidly as possible and discontinued in all cases at least one month prior to their final assessments. Disease activity was measured by standard clinical and laboratory indices, including the duration of morning stiffness, Ritchie articular score, pain expressed on a $100 \mathrm{~mm}$ visual analogue scale, grip strength, peripheral blood haemoglobin level, and erythrocyte sedimentation rate (ESR) (Westergren). From these parameters an index of disease activity (IDA) with a range of 1-4 was derived by multivariate analysis. ${ }^{8}$ The higher the IDA, the greater the disease activity.

At each assessment the absolute number of PB lymphocytes was determined from the full blood 
count and the differential count. The latter was performed by an independent assessor, who was unaware of the patients' therapy or disease status. In addition the changes in PB lymphocyte counts in $\mathbf{1 0}$ age and sex matched RA patients, after beginning D-penicillamine (DP), were examined retrospectively. The initial dose of DP was $250 \mathrm{mg}$ daily, which was increased gradually over the ensuing four months to a maintenance dose of $500 \mathrm{mg}$ daily. The follow up period for both groups of patients was similar.

Results were analysed by the Wilcoxon signed rank test and the Spearman rank correlation test.

\section{Results}

The changes in disease activity and absolute numbers of lymphocytes after the start of sodium aurothiomalate are shown in Fig. 1. Clinically, all patients showed some improvement on gold, and side effects were limited to skin rashes in three patients. In these patients the sodium aurothiomalate was discontinued prematurely, and their final assessments were included with the group at the closest cumulative dose. Improvement was most marked during the initial $500 \mathrm{mg}$ of sodium aurothiomalate, with little further change thereafter. A similar trend was seen in the absolute lymphocyte counts: all patients showed a reduction in PB lymphocytes, which ranged from 108 to $1394 / \mathrm{mm}^{3}$, $\left(0 \cdot 108 \times 10^{9}\right.$ to $\left.1.394 \times 10^{9} / \mathrm{l}\right)\left(\right.$ mean $727 / \mathrm{mm}^{3}(0 \cdot 727$ $\left.\times 10^{9} / 1\right)$ ) at their final assessment. There was poor correlation between individual changes in disease activity and absolute lymphocyte counts $(r=0 \cdot 358$ 무 $0 \cdot 10>p>0 \cdot 05)$. During treatment the tota? white cell count did not change (mean $\pm S E M$ (F) $7270 \pm 570$ v $7140 \pm 800 / \mathrm{mm}^{3} \quad\left(7 \cdot 27 \pm 0 \cdot 57 \times 10^{9} \quad\right.$ $\left.7 \cdot 14 \pm 0 \cdot 8 \times 10^{9} / 1\right)$ ) and there was a modest buf statistically insignificant rise in the total poly morphonuclear count (mean \pm SEM: $4705 \pm 470$ $5270 \pm 590 / \mathrm{mm}^{3} \quad\left(4.705 \pm 0.47 \times 10^{9} \quad v \quad 5.27 \pm 0.59\right.$ 迹 $\left.\left.10^{9} / 1\right)\right)$.

In contrast to the changes in PB lymphocytes wit $\vec{P}$ sodium aurothiomalate there was no change in the number of circulating lymphocytes in those patient ${ }^{\prime}$ receiving DP (mean \pm SEM: $1779 \pm 170 v 1713 \pm 1719$ $\left.\mathrm{mm}^{3}\left(1 \cdot 779 \pm 0 \cdot 17 \times 10^{9} \vee 1.713 \pm 0 \cdot 171 \times 10^{9} / \mathrm{l}\right)\right)$.

\section{Discussion}

The results suggest that sodium aurothiomat induces a consistent reduction in the number of $P B$ lymphocytes while modifying disease activity in RA patients. This reduction occurred shortly afte beginning gold treatment and was maintained throughout the study period. In contrast no sucto change was seen in an age and sex matched group of RA patients receiving DP. This important observao tion has not been recorded previously.

Lymphocytes are fundamentally involved i rheumatoid inflammation, and abnormalities have्尺 been found in both the numbers ${ }^{10}$ and funce tions ${ }^{11}{ }^{12}$ of various subpopulations of lymphocytes $\vec{F}$ All the patients showed some reduction in the tota $\mathrm{B}$ number of PB lymphocytes, though there was considerable variation in the degree of change. This.

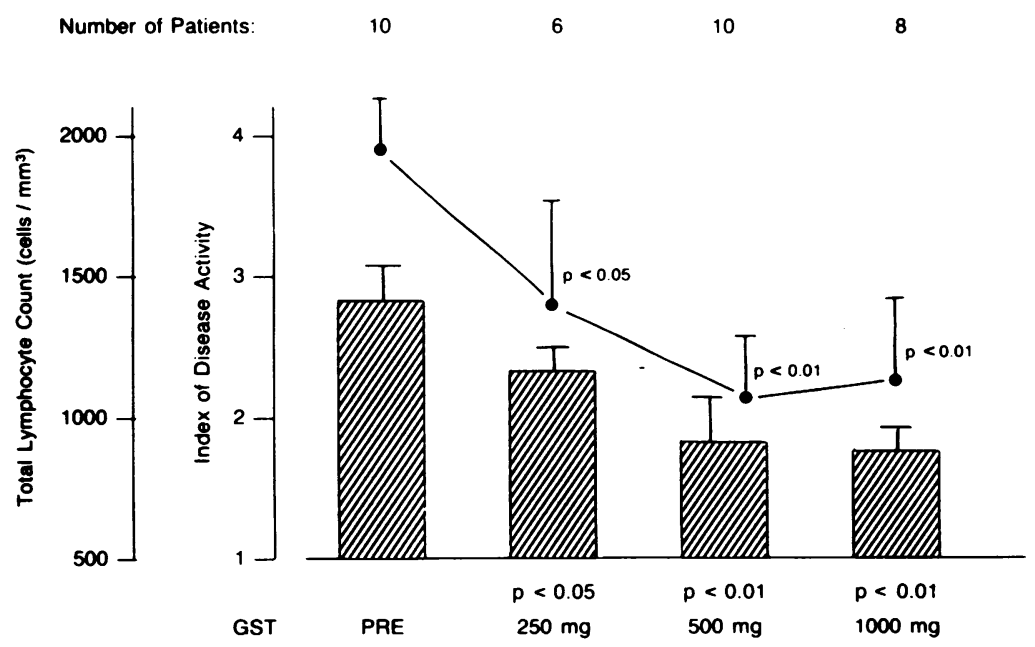

Fig. 1 The change in mean $\pm S E N$ lymphocyte count $(\longrightarrow)$ and mean $\pm S E M$ index of disease activity (shaded area) in $R A$ patients receiving sodium aurothiomalate (GST). (SI conversion: cells $/ \mathrm{mm}^{3} \times 10^{6}=$ cells/l.) 
could be explained by the selective reduction of a particular subpopulation of lymphocytes present in varying numbers before therapy. The identification of such a subpopulation might give further insight into the pathogenesis of RA and the mechanism of disease modulation by gold salts.

We are grateful to Drs M Molloy and E O'Regan, Regional Hospital, Cork, for providing data on patients receiving Dpenicillamine. Dr Hanly is the recipient of an Arthritis Foundation of Ireland Research Fellowship.

\section{References}

1 Paulus H E, Machleder H I, Levine S, Yu D T Y, MacDonald N S. Lymphocyte involvement in rheumatoid arthritis: studies during thoracic duct drainage. Arthritis Rheum 1977; 20: $1249-62$.

2 Karsh J, Klippel J H, Plotz P H, Decker J L, Wright D G, Flye M W. Lymphapheresis in rheumatoid arthritis: a randomised trial. Arthritis Rheum 1981; 24: 867-73.

3 Lipsky P E, Ziff M. Inhibition of antigen- and mitogen-induced human lymphocyte proliferation by gold compounds. J Clin Invest 1977; 59: 455-66.

4 Lies R B, Cardin C, Paulus H E. Inhibition by gold of human lymphocyte stimulation. An in vitro study. Ann Rheum Dis 1977; 36: 216-8.
5 Empire Rheumatism Council. Gold therapy in rheumatoid arthritis: final report of a multicentre controlled trial. $A n n$ Rheum Dis 1961; 20: 315-34.

6 The Cooperative Clinics Committee of the American Rheumatism Association. A controlled trial of gold salt therapy in rheumatoid arthritis. Arthritis Rheum 1973; 16: 353-8.

7 Ropes M W. Bennett G A. Cobb S. Jacox R, Jessar R A. 1958 revision of diagnostic criteria for rheumatoid arthritis. Bull Rheum Dis 1958; 9: 175-6.

8 Mallya R K. Mace B E W. The assessment of disease activity in rheumatoid arthritis using a multivariate analysis. Rheumatol Rehabil 1981; 20: 14-7.

9 Veys E M, Hermanns P. Schindler J. et al. Evaluation of T cell subsets with monoclonal antibodies in patients with rheumatoid arthritis. J Rheumatol 1982; 9: 25-9.

10 Duke O, Panayi G S, Janossy G. Poulter L W. Tidman N. Analysis of $T$ cell subsets in the peripheral blood and synovial fluid of patients with rheumatoid arthritis by means of monoclonal antibodies. Ann Rheum Dis 1983; 42: 357-61.

11 Patel V, Panayi G S. Enhanced T helper cell function for the spontaneous production of $\mathrm{IgM}$ rheumatoid factor in vitro in rheumatoid arthritis. Clin Exp Immunol 1984; 57: 584-92.

12 Chattopadhyay C, Chattopadhyay H, Natvig J B, Mechaclsen T E, Mellbye O J. Lack of suppressor cell activity in rheumatoid synovial lymphocytes. Scand J Immunol 1979; 10: 209-16. 